This accepted author manuscript is copyrighted and published by Elsevier. It is posted here by agreement between Elsevier and MTA. The definitive version of the text was subsequently published in [Current Opinion In Neurobiology, 31C: pp.26-32 , 2014 , DOI: 10.1 016/j.conb.2014.07.020]. Available under license CC-BY-NC-ND. 


\title{
Generation of physiological and pathological high frequency oscillations: the role of perisomatic inhibition in sharp-wave ripple and interictal spike generation
}

\author{
Attila I. Gulyás* and Tamás T. Freund
}

\begin{abstract}
Sharp-wave-ripple complexes (SWRs) and interictalspikes are physiological and pathological forms of irregularly occurring transient high activity events in the hippocampal EEG. They share similar features and carry high-frequency oscillations with different spectral features. Recent results reveal similarities and differences in the generation of the two types of transients, and argue that parvalbumin containing basket cells (PVBC) are crucial in synchronizing neuronal activity in both cases. SWRs are generated in the reciprocally-connected network of inhibitory PVBCs, while in the pathological case, synchronous failure of perisomatic inhibition triggers massive pyramidal cell burst firing. While physiological ripple oscillation is primarily the result of phasic perisomatic inhibitory currents, pathological high-frequency ripples are population spikes of partially synchronous, massively bursting, uninhibited pyramidal cells.
\end{abstract}

\section{Addresses \\ Institute of Experimental Medicine, Hungarian Academy of Sciences, Budapest, Hungary; Szigony u 43. Budapest, Hungary, $\mathrm{H}-1083$}

Corresponding author: Attila I Gulyas, gulyas@koki.hu

\section{Introduction}

A subset of physiological and pathological brain activity patterns is not periodic oscillations, but network bursts. These irregularly-occurring, transient, high activity events (THAEs) carry distinct forms of superimposed high frequency oscillations (HFOs) [1-4]. Many phenomena are lumped under HFOs [5] including high-frequency gamma $(80-100 \mathrm{~Hz})$, epsilon [6], ripples $(140-200 \mathrm{~Hz})$ that can be a part of physiological and pathological events [7], and fast ripples (fRIPs, 200-800Hz) that appear exclusively in pathological cases [8-10] but often alternate with ripples in the physiological range within the same transient. Sharp-wave-ripple complexes (SWR) are recurring physiological transients $[3,11]$ that are essential for memory consolidation [12-14] and are ornamented with ripple oscillations in the $140-200 \mathrm{~Hz}$ range [15]. Pathological forms of THAEs are the interictal spikes (IIS) and their different, iterated, transitional forms: recital and octal sequences. These pathological transients are associated with fRIPs in the 200$800 \mathrm{~Hz}$ range $[16,17]$. Hippocampal fRIPs were shown to be associated with hippocampal sclerosis, cell loss and the epileptic focus. They appear at the onset of epileptic events $[8,17-19]$, and therefore have diagnostic value in that they can be used to predict and localize epileptic seizures [20]. Ripples and fRIPs have been shown to be different phenomena [21], but experiments suggested they are related, since, in the human epileptic hippocampus, fRIPs emerged from ripples [22].

The two primary questions examined in this review are:

1) how are irregularly-recurring physiological (SWRs) and pathological (IISs) THAEs initiated?

2) How are overlaid HFOs generated, and what is the role of inhibition in the generation of synchrony?

Additional important questions are:

3) what is the difference in the generation mechanisms of healthy and pathological ripples and fast-ripples?

4) What is the contribution of synaptic currents versus synchronized action potentials (population spikes) to the generation of different forms of ripples?

\section{Physiological sharp waves and ripples}

Sharp-waves have been described in the hippocampal CA1 area of rats and were shown to propagate from the CA3 area [23]. It has been suggested that the recurrent collateral system of CA3 PCs is essential for the generation of SWRs, which are then transferred to CA1 via the Schaffer collaterals [24]. The low frequency envelope is accompanied by a high frequency component, the ripple $(140-200 \mathrm{~Hz}$ [15]), that is manifested as sink-source pairs in and around stratum pyramidale $[25,26]$ in both CA3 and CA1. During SWRs, inhibitory neurons and PCs fire phase-locked to the ripple oscillation [24,27]. Periodic perisomatic inhibition has been held responsible for the generation of the high-frequency components and the phaselocking of neuronal activity [3], but no convincing data are available about the initiation of SWRs, although the SWR state is considered an "off-line" state of the hippocampus [12].

To uncover the participation of different types of neurons in SWR generation, several in vivo [28-34] and in vitro [35-37] studies have examined the firing characteristics of identified neuron types (summarized in [38]). Mostly similar relative firing patterns were found for the examined cell types, but there were some contradictory results, which might have arisen from differences between the CA1 and the CA3 area, and most importantly from anaesthetized compared to freely moving animals or in vitro slices. In general, individual PCs were found to fire infrequently during subsets of SWRs. The most active cells with ripple phase-locked spikes were the parvalbuminpositive basket cells (PVBC). Axo-axonic cells (AACs) fired transiently at the beginning of SWRs. CCK basket, but not dendritic, cells were inhibited during SWRs. Ivy cells were found to have sparse activity that was not modified during SWRs. A more complicated picture emerged for the SOM+ cells, and depended on the circumstances and subtype. OLM cells could be inhibited or activated, while bistratified cells fired during SWRs.

The proposed mechanisms for ripple generation during SWRs must resolve two issues: what generates the currents, and what generates the ripple timing.

One hypothesis, based on neuronal network modeling [39], is that gap junctions among pyramidal cell (PC) axons form the basis of the ripple oscillation. However, this has been questioned both by other modeling studies [40] and also by experimenters due to the fact that all known gap junction blockers are "dirty drugs" [41,42]. Furthermore, the idea of short-circuiting pyramidal cell axons in order to explain ripple oscillations goes against the established principle that the PC population activity carries highly specific representational information. A second model proposes a feedback loop among PCs and inhibitory neurons $[3,15,28,40]$ similar to the mechanism proposed for gamma oscillation generation $[43,44]$. The problem with this scenario is that the frequency of this mechanism can not be up-scaled to the ripple range [40]. Finally, reciprocal inhibition among inhibitory neurons was proposed as a generator of ripple oscillations [40,45-48]. This scenario is supported by the findings that ripple oscillations in CA3 and CA1 have slightly different frequencies and are therefore not coherent $[15,33]$. This means that ripples are not transmitted cycle by cycle through the Schaffer collaterals (as required in the second scenario above), but must be locally 
generated in both areas. The reciprocal inhibitory mechanism satisfies this criterion.

\section{Epileptic activity and pathological fast ripples}

Miles and his collaborators [49-51] proposed a mechanism for the non-periodic initiation of epileptiform events, where stochastic activity in a single PC launches a prolonged buildup of excitatory activity in the recurrent collaterals of the CA3 area, and evokes an epileptic event.

Since their discovery [16], the generation of ripples and fast ripples has been reviewed many times [5,8,52-54]. Loss of inhibition turns ripples into fast ripples [55]. fRIPs persist after GABAA receptor blockade [22], suggesting their independence from functional inhibition. There is a reasonable agreement on the generation of fast ripples. It was first suggested [16] and then proven $[22,56]$ that synchronized burst firing of PCs is important in fRIP generation, and that they are actually population spikes. Oscillations at frequencies far higher than the maximum firing rate of a pyramidal cell arise when PC subpopulations commence out-of-phase synchronized firing $[22,57]$. The mechanisms causing (partial) synchrony are not yet clear. The usual suspects, gap junction coupling and ephaptic interactions, have been blamed [39]. However, the facts are: 1) experimental manipulation of PC burst precision [56] reduces fast ripple amplitude and 2) there is a frequency shift and a drop in the amplitude during HFOs [52,58], and fast ripples show large spectral fluctuation [20,54]. This suggests that the simultaneous onset of bursting in large populations of $\mathrm{PCs}$ can result in pseudo-synchrony and fast ripples, without any special synchronization mechanism among PCs.

\section{The difference between SWRs and IISs: mechanisms of physiological and pathological transient high activity event generation in vitro}

As for all EEG signals, synaptic currents and synchronized action potentials are considered as the components that underlie the LFP during SWRs and IISs in stratum pyramidale. It has been suggested that summated perisomatic inhibitory currents contribute to SWRs [3]. Population spikes from clusters of abnormally synchronously bursting neurons were suggested to contribute to IISs [59]. As stated above, the fact that GABAergic mechanisms do not seem to contribute to fRIP generation suggests that inhibitory currents do not play a role in pathological LFP generation. Besides these suggestions, no definitive experiments have been made to directly examine the contribution of the two candidate mechanisms.

Therefore, in a recent series of studies in our laboratory $[36,60,61]$ we examined the differences between physiological and pathological network bursts in the CA3 area, where they are generated. The experiments verified earlier proposals and showed how SWRs and IISs are generated in the CA3 area of mouse hippocampal slices. A modified in vitro submerged slice preparation was used [62] that allowed measurement of network and cellular activity from slices that generate in vivolike high activity levels and patterns. The preparation allows quick and selective manipulation of network interactions and parallel recording of network dynamics, as well as the activity of identified neuron types and populations.

\section{SWRs are initiated by PC activity, and shaped by inhibition deriving from reciprocally connected PVBCs}

Based on the idea of a buildup of activity in the recurrent collaterals of CA3 PCs [51], it was shown that SWRs are initiated in the CA3 area through a combined refractory and stochastic mechanism[61]. When firing coincides in a set of spontaneously active pyramidal cells, it triggers a gradual, exponential build-up of activity in the recurrent CA3 network and a SWR is initiated. Perisomatic inhibition from PVBCs (but not from CCK-containing basket cells) proved to be necessary and sufficient for ripple oscillation generation. Tonic excitation from the activated PCs provided the drive to PVBCs, which phase-lock their firing at ripple frequency due to their reciprocal inhibitory connections, described as the Fast Inhibitory Neuron Oscillation (FINO) mechanism by Schlingloff et al [61]. This configuration is different from the Pyramidal cell Inhibitory Network Gamma (PING) mechanism, where a reciprocal interaction between the two cell types generates gamma oscillations [63] at a lower frequency, and also for the thalamic generation of spindles [4], where similar excitatoryinhibitory out of phase firing generates the oscillation. The synchronized GABAA receptor-mediated currents from the PVBCs give rise to a major component of the ripple-frequency oscillation in the local field potential, and phase-modulate the rather sparse tonic spiking of pyramidal cells, which also contribute somewhat to the ripple local field potential. Counter intuitively, the results also suggested that PVBC activity not only synchronized, but also promoted, PC firing, since transient optogenetic activation of PVBCs evoked full SWRs and $P C$ activity.

From the three possible models, the experiments excluded the role of gap junctions and also eliminated the reciprocal PCinhibitory neuron loop model [61]. Gap junctions were excluded because a small cut at the border of str.pyramidale and lucidum that severed PVBC axonal connectivity, but not gap junctions (they can be found out in str. lacunosum moleculare and oriens) eliminated synchrony of ripple activity in the two halves of the cut. The reciprocal PC-PVBC model was eliminated because tonic driving pf PVBCs is sufficient to evoke ripple oscillation; phasic PC activity is not required for this. These experiments prove what has been suggested earlier; the current generator of ripple oscillations in stratum pyramidale is primarily the phasic perisomatic inhibition $[3,15]$ from PVBCs and, to a smaller extent, phase-locked PC action potentials.

\section{Generation of interictal spikes: changes in cellular and network parameters result in degeneration of physiological SWRs and generation of pathological HFOs}

To study the difference in the behavior of distinct cell types and how cellular and network parameters change during the epileptogenic state, epileptic activity was induced in four different ways (ACSF modified with high [K+], 4-AP, low [Mg2+] and gabazine) in the slice preparation [60]. It was found that: 1)upon induction of epileptic activity, spontaneously generated SWRs in CA3 disappeared and, following an asynchronous transitory phase, activity reorganized into a new form of pathological synchrony in the form of IIS and other more complex epileptiform events; 2) during epileptiform events, all neurons increased their firing rate compared to SWRs; 3) different cell types showed complementary firing: PVBCs and some AACs stopped firing nearly simultaneously due to a depolarization block at the climax of the events. In contrast, pyramidal cells started firing bursts at this point. This moment was also marked by the onset of HFOs in the LFP; 4) compared to the SWR-generating state, the cellular excitability increased and excitatory transmission was enhanced, whereas inhibitory transmission (both somatic and dendritic) was compromised; 5) additionally, a strong short-term depression was also observed in the PVBC to PC transmission.

Aivar et al (2014) [64] induced similar transitions from healthy to pathological forms of ripples by decreasing [Ca2+]e. They found similar shifts in excitability parameters and transmission parameters and concluded, similarly, that failure of inhibition results in strong PC firing that shapes the fRIPs. The importance of PVBCs in seizure propagation has been recently demonstrated [65]. It was also reported that some neurons can enter into depolarization blocks during seizures $[66,67]$. We 

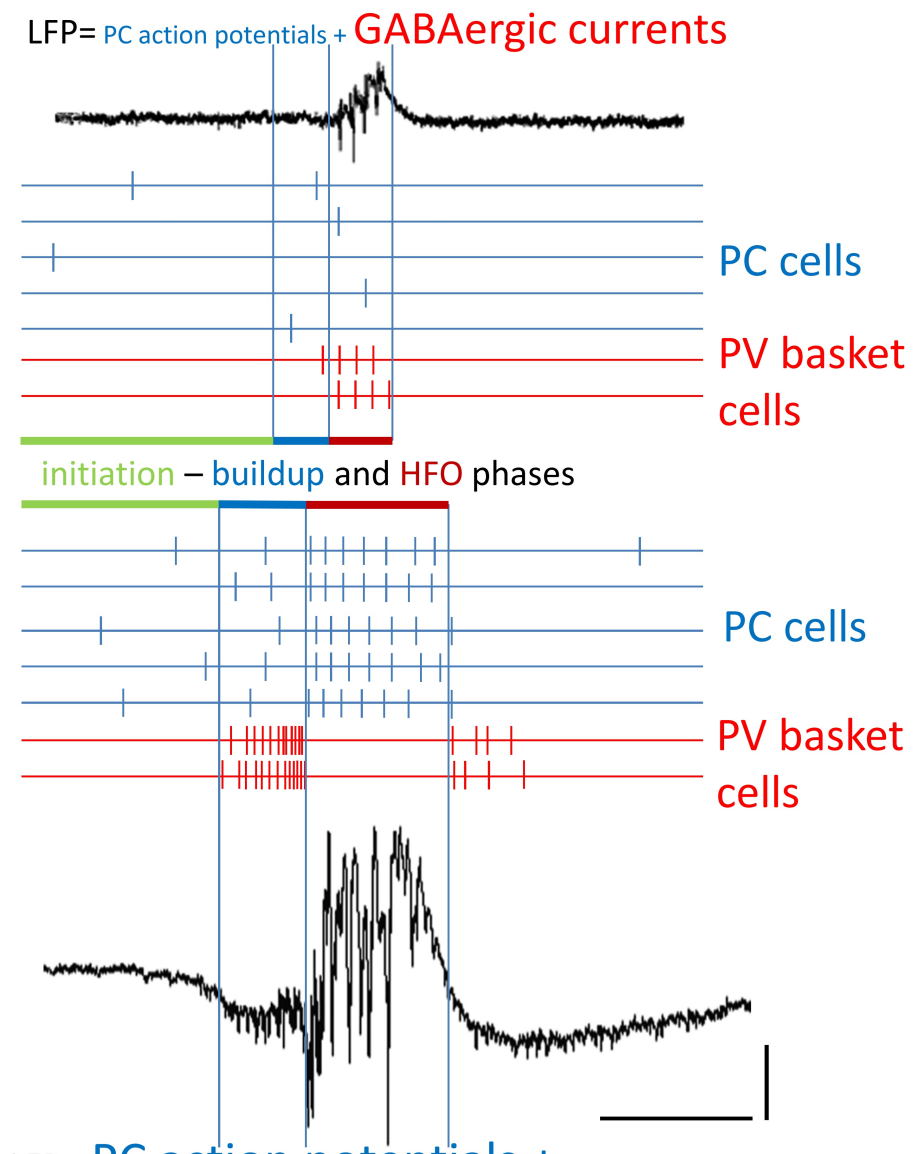

$\mathrm{LFP}=\mathrm{PC}$ action potentials + GABAergic currents

have to note however that the fate of dendritic inhibition is different. While we reported a failure in perisomatic GABAergic transmission an increased GABA release was observed during epileptic events $[68,69]$. This suggests that dendritic inhibition does not fail. Our findings that besides the PV-positive cells most inhibitory neurons increased their firing frequency during epileptic events [60] and while PVBCs show a strong shortterm depression usually dendritic neurons show short-term facilitation (unpublished observation) agrees with increased dendritic GABA transmission. Yet pyramidal cells start to fire at the collapse of perisomatic inhibition, suggesting that dendritic control is not sufficient.

Thus, SWRs and IIS have similarities and differences in their generating mechanisms (see Figure 1 and Table 1). They share an identical initiation mechanism, where stochastic activity of pyramidal cells triggers the buildup of excitatory activity. Following this phase, in the case of SWRs, PVBCs are activated at the appropriate time and only to a physiological level, so their activity can then shape the evolution of SWRs by phase-locking (and paradoxically even promoting[61]) PC activity. In the case of IIS, the excitatory buildup is much quicker most probably as a result of increased excitability, and increased excitatory synaptic transmission that is only countered by a weakened inhibition. Therefore, PVBCs will receive excitation that drives them into depolarization block (and their already weakened transmission breaks down due to strong short-term depression), resulting in an uncontrolled burst firing in all PCs $[22,70]$. The similarities between these phenomena suggests that IIS are degenerate forms of SWR and, as concluded previously [4], "epileptic events hijack normal circuitry".

The abrupt collapse of pyramidal cell perisomatic inhibition appears to be a crucial factor in the emergence of epileptiform events and in the generation of pathological fast ripples. Fast ripples thus indicate collapse of perisomatic inhibition and the uncontrolled firing of PCs. This explains why HFOs correlate with the onset of epileptiform activity [8,17-19], are found in the epileptic focus $[16,17]$ and are a good diagnostic feature
SWRs and IIS have similar phases during their evolution: Similar phases can be distinguished in the two types of transient high activity events (SWR: top half, IIS: bottom half). Initiation is based on a stochastic-refractory model, where activity starts in a few spontaneously active neurons. In the case of IISs, the inter-event interval is probably mostly influenced by recovery of high spontaneous activity from different refractory mechanisms. During buildup, the activity evolves in the recurrent collateral system of the CA3 in both cases. It is much stronger in the epileptic case due to high excitability and increased excitatory, but decreased inhibitory, transmission. The strong buildup in the HFO phase alters the behavior of PVpositive basket cells. While they produce ripple synchrony and ripple phase-locked PC firing through the FINO mechanism during SWRs, due to pathologically high excitation, PVBCs enter into depolarization block. The simultaneous cessation of perisomatic inhibition results in uncontrolled and pseudo-synchronous bursting in all PCs, and manifests as fRIPs with a shifting dominant frequency. Black traces indicate an LFP recording of a SWR and an IIS from the same in vitro mouse hippocampal slice in normal (SWR) and epileptogenic ACSF (IIS). Blue and red rasters indicate the firing of PCs and PVBCs in the two cases. Scale $100 \mathrm{msec}, 100 \mu \mathrm{V}$.

\section{PVBC-mediated inhibition in physiological and pathological synchrony: success or failure influences the composition of local field potentials}

Our recent results suggest that in the case of SWRs, the rhythm is generated when tonic excitation drives the reciprocally-connected inhibitory network of PVBCs (FINO mechanism) that, through periodic perisomatic IPSPs, phaselock themselves and the sparsely-firing PCs. PVBCs - more correctly the failure of their inhibition- is also crucial for fastripple generation, since at the end of the buildup period, PVBCs enter concurrently into depolarization block, and pyramidal cell burst firing starts simultaneously at this time, producing pseudo-synchronous spikes without a synchronizing mechanism. With time, this synchrony breaks down, as demonstrated first by the quickening of the pathological ripple and then by the decrease of power in the high frequency bands [52,58]. These findings explain Bragin et al's [16] original observation and support the consensus on RIP and fRIP generation $[5,8,52-54]$ by showing that the LFP is dominated by inhibitory synaptic currents during SWRs [61] and by PC action potentials during IISs [60]. When inhibition fails during IIS, the balance is tipped in the same direction by the two counteracting mechanisms; on one side, the inhibitory synaptic currents disappear, while on the other side pyramidal cells start to fire en mass and the population spikes of their APs form the LFP signal of fast ripples (see also [64] fig 9). Fast ripples thus appear when and where inhibitory control is lost and massive PC firing erupts [71].

\section{Conclusions}

Similar to the case of gamma oscillations, PVBCs proved to be essential timekeepers during the ripple oscillation phase of sharp waves, but since they are driven more strongly, they are engaged in a different rhythm generating mode (FINO instead 


\section{TABLE}

Differences in the generation mechanisms of physiological and pathological transient high activity events

\begin{tabular}{|c|c|c|}
\hline network state & SWR (physiological) & IIS (pathological) \\
\hline \multicolumn{3}{|l|}{ parameter values } \\
\hline excitability & low & High \\
\hline E to E strength & normal & Increased \\
\hline I- to $E$, I to I strength & normal & Decreased \\
\hline initiation & stochastic + refractory mechanism & $\begin{array}{l}\text { stochastic + refractory mechanism, refractoriness dominates during } \\
\text { preictal and ictal activity }\end{array}$ \\
\hline \multicolumn{3}{|l|}{$\begin{array}{l}\text { initiation, buildup } \\
\text { phase }\end{array}$} \\
\hline PC activity & spontaneous, very low freq. firing & elevated firing, many cell bursts \\
\hline PVBC activity & silent & elevated firing \\
\hline other IN activity & silent or occasional spikes & elevated firing \\
\hline inhibitory transmission & strong & weak \\
\hline \multicolumn{3}{|l|}{ during HFO } \\
\hline PC activity & $10 \%$ of cells fire, single spikes & all firing, bursts \\
\hline PVBC activity & ripple phase-locked firing & depolarization block, no spikes \\
\hline other IN activity & low freq single spikes & high frequency spiking \\
\hline inhibitory transmission & short-term depression & collapsed, no transmission from PVBC terminals \\
\hline HFO type & ripples $(140-200 \mathrm{~Hz})$ & fast ripples $(200-800 \mathrm{~Hz}, \mathrm{pHFO})$ \\
\hline source of synchrony & $\begin{array}{l}\text { FINO: excitation drives PVBCs that phase-lock their firing via } \\
\text { reciprocal inhibition }\end{array}$ & $\begin{array}{l}\text { simultaneous depolarization block of PVBCs releases PCs from } \\
\text { inhibition concurrently. PCs start to burst simultaneously and } \\
\text { pseudo synchrony evolves, until PC APs fall out of phase }\end{array}$ \\
\hline LFP components & $\begin{array}{l}\text { mostly perisomatic GABAergic currents, a minor contribution } \\
\text { of phase-locked PC APs }\end{array}$ & $\begin{array}{l}\text { no GABAergic currents, partially synchronized bursting PC APs } \\
\text { (population spikes) }\end{array}$ \\
\hline
\end{tabular}

of PING). They also proved to be key figures in synchronizing the onset of PC burst firing through their simultaneous failure at the beginning of fRIPs. The fact that PVBCs were found to be necessary and sufficient for ripple generation, while other inhibitory neurons did not contribute significantly, matches the proposal of Freund and Katona, 2007 [72] that PVBCs are essentially time-keepers that effectuate rhythms, while other neurons (like CCK-containing basket cells) must implement more subtle functions associated with subcortical modulatory switches among behavioral states. To reveal the function of these neurons e.g. in mediating motivational and emotional impact, more sensitive in vivo experiments are needed.

\section{Outlook, Future directions}

We want to emphasize two points concerning future research. Both include a technical point: First, in order to understand the contribution of a cell type to the generation of network activity, it is insufficient to simply measure its firing pattern, but functional transmission also has to be measured during the relevant state and with the relevant pattern. We showed that even if PVBCs are firing at some stages of epileptic events, their terminals do not release GABA from the middle of an epileptic train of action potentials onwards [60]. We previously found a similar failure of transmission in the case of CCKpositive cells during the gamma-generating high cholinergic state [73]: although they fire gamma phase associated action potentials, there is no GABA release from their terminals. Similarly, basic cellular and network parameters have to be measured in different states because they influence network dynamics. Second: It seems essential to detect HFOs and multiunit activity in recordings from epileptic patients, since the timing and location of fRIPs proved to be diagnostic concerning the origin of epileptic events. Similarly, the reorganization of multiunit activity $[74,75,60]$ and of HFO structure [20] preceding epileptic activity cannot be detected in the low frequency components of the LFP. Therefore in high sampling rate (over $100 \mathrm{~Hz}$ ) recordings should be routinely used in diagnostic measurements of epileptic patients.

\section{Highlights}

-tonic excitation of reciprocally-connected PVBCs evokes ripple frequency firing

-physiological ripples are primarily perisomatically-generated inhibitory currents

-IISs are degenerate forms of SWRs, when inhibition collapses -altered excitability and E/I balance accelerate buildup during initiation of an IIS

-fast ripples are population spikes of pseudo-synchronized PCs bursts

\section{Acknowledgements}

The authors work was supported by the Hungarian Scientific Research Fund (OTKA K83251, NNF 85659), European Research Council (ERC-2011-ADG-294313; SERRACO) and the EU FP grant no. 604102 (Human Brain Project).

\section{References and recommended reading}

* of special interest

** of outstanding interest

REFERENCES

\section{$1 . \quad$ Buzsaki G, Czopf J, Kondakor I, Kellenyi L: Laminar} distribution of hippocampal rhythmic slow activity (RSA) in the behaving rat:current-source density analysis, effects of urethane and atropine. Brain Res 1986, 365PBS Record: 127:125-137.

2. Bragin A, Engel J Jr, Wilson CL, Fried I, Mathern GW: Hippocampal and entorhinal cortex high-frequency oscillations (100$500 \mathrm{~Hz}$ ) in human epileptic brain and in kainic acid--treated rats with chronic seizures. Epilepsia 1999, 40:127-137.

3. Ylinen A, Bragin A, Nadasdy Z, Jando G, Szabo I, Sik A, Buzsaki G: Sharp wave-associated high-frequency oscillation $(200 \mathrm{~Hz})$ in the intact hippocampus: network and intracellular mechanisms. J Neurosci 1995, 15:30-46.

4. Beenhakker MP, Huguenard JR: Neurons that fire together also conspire together: is normal sleep circuitry hijacked to generate epilepsy? Neuron 2009, 62:612-632.

** a comprehensive, also at some places outdated comparison on the generation of hippocampal shrap-waves and thalamocortical spindfle oscillatons, with deep insights

5. Jefferys JGR, Menendez de la Prida L, Wendling F, Bragin A, Avoli M, Timofeev I, Lopes da Silva FH: Mechanisms of physiological 
and epileptic HFO generation. Prog. Neurobiol. 2012, 98:250-264. * detailed review on the types and proposed mechanisms of high frequency oscillations

6. Scheffer-Teixeira R, Belchior H, Leão RN, Ribeiro S, Tort ABL: On high-frequency field oscillations $(>100 \mathrm{~Hz})$ and the spectral leakage of spiking activity. J. Neurosci. Off. J. Soc. Neurosci. 2013

33:1535-1539.

7. Lévesque M, Bortel A, Gotman J, Avoli M: High-frequency

(80-500 Hz) oscillations and epileptogenesis in temporal lobe epilepsy. Neurobiol. Dis. 2011, 42:231-241.

8. Staba RJ: Normal and Pathologic High-Frequency

Oscillations [Internet]. In Jasper's Basic Mechanisms of the Epilepsies Edited by Noebels JL, Avoli M, Rogawski MA, Olsen RW, DelgadoEscueta AV. National Center for Biotechnology Information (US); 2012. 9. Bragin A, Wilson CL, Almajano J, Mody I, Engel J: Highfrequency oscillations after status epilepticus: epileptogenesis and seizure genesis. Epilepsia 2004, 45:1017-1023.

10. Jiruska P, Csicsvari J, Powell AD, Fox JE, Chang W-C Vreugdenhil M, Li X, Palus M, Bujan AF, Dearden RW, et al.: HighFrequency Network Activity, Global Increase in Neuronal Activity, and Synchrony Expansion Precede Epileptic Seizures In Vitro. J. Neurosci. 2010, 30:5690 -5701.

11. Buzsaki G: Hippocampal sharp waves: their origin and significance. Brain Res 1986, 398:242-252.

12. Buzsaki G: Two-stage model of memory trace formation: A role for "noisy" brain states. Neuroscience 1989, 31:551-570.

13. Girardeau G, Benchenane K, Wiener SI, Buzsaki G, Zugaro MB: Selective suppression of hippocampal ripples impairs spatial memory. Nat Neurosci 2009, 12:1222-1223.

14. Jadhav SP, Kemere C, German PW, Frank LM: Awake Hippocampal Sharp-Wave Ripples Support Spatial Memory [Internet]. Science 2012, doi:10.1126/science.1217230.

15. Buzsaki G, Horvath Z, Urioste R, Hetke J, Wise K: Highfrequency network oscillation in the hippocampus. Science 1992 256PBS Record: 1704:1025-1027.

16. Bragin A, Engel J Jr, Wilson CL, Fried I, Buzsáki G: Highfrequency oscillations in human brain. Hippocampus 1999, 9:137-142. 17. Bragin A, Engel J Jr, Staba RJ: High-frequency oscillations in epileptic brain. Curr. Opin. Neurol. 2010, 23:151-156.

18. Staba RJ, Frighetto L, Behnke EJ, Mathern GW, Fields T, Bragin A, Ogren J, Fried I, Wilson CL, Engel J Jr: Increased fast ripple to ripple ratios correlate with reduced hippocampal volumes and neuron loss in temporal lobe epilepsy patients. Epilepsia 2007, 48:2130-2138. 19. Ogren JA, Wilson CL, Bragin A, Lin JJ, Salamon N, Dutton RA, Luders E, Fields TA, Fried I, Toga AW, et al.: Three-dimensional surface maps link local atrophy and fast ripples in human epileptic hippocampus. Ann. Neurol. 2009, 66:783-791.

20. Pearce A, Wulsin D, Blanco JA, Krieger A, Litt B, Stacey WC: Temporal changes of neocortical high-frequency oscillations in epilepsy. J. Neurophysiol. 2013, 110:1167-1179.

21. Bragin A, Wilson CL, Staba RJ, Reddick M, Fried I, Engel J: Interictal high-frequency oscillations $(80-500 \mathrm{~Hz})$ in the human epileptic brain: entorhinal cortex. Ann. Neurol. 2002, 52:407-415.

22. Foffani G, Uzcategui YG, Gal B, Menendez de la Prida L: Reduced spike-timing reliability correlates with the emergence of fast ripples in the rat epileptic hippocampus. Neuron 2007, 55:930-41. 23. Buzsáki G, Leung LW, Vanderwolf $\mathrm{CH}$ : Cellular bases of hippocampal EEG in the behaving rat. Brain Res. 1983, 287:139-171. 24. Csicsvari J, Hirase H, Mamiya A, Buzsáki G: Ensemble patterns of hippocampal CA3-CA1 neurons during sharp waveassociated population events. Neuron 2000, 28:585-94.

25. Isomura Y, Sirota A, Ozen S, Montgomery S, Mizuseki K, Henze DA, Buzsáki G: Integration and segregation of activity in entorhinal-hippocampal subregions by neocortical slow oscillations. Neuron 2006, 52:871-82.

26. Ellender TJ, Nissen W, Colgin LL, Mann EO, Paulsen O: Priming of hippocampal population bursts by individual perisomatictargeting interneurons. J. Neurosci. Off. J. Soc. Neurosci. 2010, 30:5979-5991.

27. Csicsvari J, Hirase H, Czurko A, Mamiya A, Buzsaki G: Oscillatory coupling of hippocampal pyramidal cells and interneurons in the behaving Rat. J Neurosci 1999, 19:274-87.

28. Klausberger T, Magill PJ, Marton LF, Roberts JD, Cobden PM, Buzsaki G, Somogyi P: Brain-state- and cell-type-specific firing of hippocampal interneurons in vivo. Nature 2003, 421:844-8. 29. Klausberger T, Marton LF, O'Neill J, Huck JH, Dalezios Y, Fuentealba P, Suen WY, Papp E, Kaneko T, Watanabe M, et al.: Complementary roles of cholecystokinin- and parvalbumin-expressing GABAergic neurons in hippocampal network oscillations. J Neurosci 2005, 25:9782-93.

30. Fuentealba P, Begum R, Capogna M, Jinno S, Márton LF, Csicsvari J, Thomson A, Somogyi P, Klausberger T: Ivy cells: a population of nitric-oxide-producing, slow-spiking GABAergic neurons and their involvement in hippocampal network activity. Neuron 2008, 57:917-29.

31. Lasztóczi B, Tukker JJ, Somogyi P, Klausberger T: Terminal field and firing selectivity of cholecystokinin-expressing interneurons in the hippocampal CA3 area. J. Neurosci. Off. J. Soc. Neurosci. 2011, 31:18073-18093

32. Lapray D, Lasztoczi B, Lagler M, Viney TJ, Katona L, Valenti O, Hartwich K, Borhegyi Z, Somogyi P, Klausberger T: Behaviordependent specialization of identified hippocampal interneurons. Nat. Neurosci. 2012, 15:1265-1271.

33. Tukker JJ, Lasztóczi B, Katona L, Roberts JDB, Pissadaki EK, Dalezios Y, Márton L, Zhang L, Klausberger T, Somogyi P: Distinct dendritic arborization and in vivo firing patterns of parvalbuminexpressing basket cells in the hippocampal area CA3. J. Neurosci. Off. J. Soc. Neurosci. 2013, 33:6809-6825.

34. Varga C, Golshani P, Soltesz I: Frequency-invariant temporal ordering of interneuronal discharges during hippocampal oscillations in awake mice. Proc. Natl. Acad. Sci. U. S. A. 2012, 109:E2726-2734.

35. Pangalos M, Donoso JR, Winterer J, Zivkovic AR, Kempter R, Maier N, Schmitz D: Recruitment of oriens-lacunosum-moleculare interneurons during hippocampal ripples. Proc. Natl. Acad. Sci. U. S. A. 2013, 110:4398-4403.

36. Hájos N, Karlócai MR, Németh B, Ulbert I, Monyer H, Szabó G, Erdélyi F, Freund TF, Gulyás Al: Input-output features of anatomically identified CA3 neurons during hippocampal sharp wave/ripple oscillation in vitro. J. Neurosci. Off. J. Soc. Neurosci. 2013, 33:11677-11691.

37. Sasaki T, Matsuki N, Ikegaya Y: Interneuron firing precedes sequential activation of neuronal ensembles in hippocampal slices. Eur. J. Neurosci. 2014, doi:10.1111/ejn.12554.

38. Somogyi P, Katona L, Klausberger T, Lasztóczi B, Viney TJ: Temporal redistribution of inhibition over neuronal subcellular domains underlies state-dependent rhythmic change of excitability in the hippocampus. Philos. Trans. R. Soc. Lond. B. Biol. Sci. 2014, 369:20120518.

* most up to date review on firing of different neuron types during SWR and theta state, compares results in freely moving vs. anaesthetized animals

39. Draguhn A, Traub RD, Schmitz D, Jefferys JGR: Electrical coupling underlies high-frequency oscillations in the hippocampus in vitro. Nature 1998, 394:189-192.

40. Brunel N, Wang X-J: What determines the frequency of fast network oscillations with irregular neural discharges? I. Synaptic dynamics and excitation-inhibition balance. J. Neurophysiol. 2003, 90:415-430.

41. Behrens CJ, UI Haq R, Liotta A, Anderson ML, Heinemann U: Nonspecific effects of the gap junction blocker mefloquine on fast hippocampal network oscillations in the adult rat in vitro. Neuroscience 2011, 192:11-19.

42. Connors BW: Tales of a Dirty Drug: Carbenoxolone, Gap Junctions, and Seizures. Epilepsy Curr. 2012, 12:66-68.

43. Whittington MA, Traub RD, Kopell N, Ermentrout B, Buhl EH: Inhibition-based rhythms: experimental and mathematical observations on network dynamics. Int J Psychophysiol 2000, 38:315-36.

44. Mann EO, Suckling JM, Hajos N, Greenfield SA, Paulsen O: Perisomatic feedback inhibition underlies cholinergically induced fast network oscillations in the rat hippocampus in vitro. Neuron 2005 , 45:105-17.

45. Perkel DH, Mulloney B: Motor pattern production in reciprocally inhibitory neurons exhibiting postinhibitory rebound. Science 1974, 185PBS Record: 2305:181-183.

46. Taxidis J, Coombes S, Mason R, Owen MR: Modeling sharp wave-ripple complexes through a CA3-CA1 network model with chemical synapses. Hippocampus 2012, 22:995-1017.

47. Schomburg EW, Anastassiou CA, Buzsáki G, Koch C: The spiking component of oscillatory extracellular potentials in the rat hippocampus. J. Neurosci. Off. J. Soc. Neurosci. 2012, 32:11798-11811.

48. Cutsuridis V, Taxidis J: Deciphering the role of CA1 inhibitory circuits in sharp wave-ripple complexes. Front. Syst. Neurosci. 2013, $7: 13$.

49. Miles R, Wong RK: Single neurones can initiate synchronized population discharge in the hippocampus. Nature 1983, 306PBS Record: $534: 371-373$.

50. Cohen I, Navarro V, Clemenceau S, Baulac M, Miles R: On the origin of interictal activity in human temporal lobe epilepsy in vitro. Science 2002, 298:1418-21.

51. Menendez de la Prida LM, Huberfeld G, Cohen I, Miles R: Threshold behavior in the initiation of hippocampal population bursts. Neuron 2006, 49:131-142.

* the paper that proposes the buildup mechanism for epileptic event initiation 
and clinical epileptic foci. Epilepsy Res. 2011, 97:300-307.

53. Köhling R, Staley K: Network mechanisms for fast ripple

activity in epileptic tissue. Epilepsy Res. 2011, 97:318-323.

54. Menendez de la Prida L, Trevelyan AJ: Cellular mechanisms

of high frequency oscillations in epilepsy: on the diverse sources of

pathological activities. Epilepsy Res. 2011, 97:308-317.

55. Behrens CJ, van den Boom LP, Heinemann U: Effects of the

$\mathrm{GABA}(\mathrm{A})$ receptor antagonists bicuculline and gabazine on stimulus-

induced sharp wave-ripple complexes in adult rat hippocampus in vitro.

Eur. J. Neurosci. 2007, 25:2170-2181.

56. Dzhala VI, Staley KJ: Mechanisms of Fast Ripples in the

Hippocampus. J. Neurosci. 2004, 24:8896-8906.

* the paper demonstrate causal relationship between burst firing and HFO generation

57. Ibarz JM, Foffani G, Cid E, Inostroza M, Menendez de la Prida L: Emergent Dynamics of Fast Ripples in the Epileptic

Hippocampus. J Neurosci 2010, 30:16249-16261.

58. Lévesque M, Salami P, Gotman J, Avoli M: Two seizure-onset types reveal specific patterns of high-frequency oscillations in a model of temporal lobe epilepsy. J. Neurosci. Off. J. Soc. Neurosci. 2012 32:13264-13272.

59. Bragin A, Wilson CL, Engel J: Voltage depth profiles of highfrequency oscillations after kainic acid-induced status epilepticus.

Epilepsia 2007, 48 Suppl 5:35-40.

60. Karlócai MR, Kohus Z, Káli S, Ulbert I, Szabó G, Máté Z

Freund TF, Gulyás Al: Physiological sharp wave-ripples and interictal events in vitro: what's the difference? Brain 2014,

doi:10.1093/brain/awt348.

* the study reveals the similarities and differences in the generation of physiological sharp-wave ripples and interictal events

61. Schlingloff D, Kali S, Freund TF, Hájos N, Gulyás Al:

Mechanisms of sharp wave initiation and ripple generation. J Neurosci 2014 , in press.

* the study demonstrates the initiation and generation mechanisms of sharp-wavaes and ripples

62. Hájos N, Ellender TJ, Zemankovics R, Mann EO, Exley R, Cragg SJ, Freund TF, Paulsen O: Maintaining network activity in submerged hippocampal slices: importance of oxygen supply. Eur. J. Neurosci. 2009, 29:319-327.

63. Mann EO, Radcliffe CA, Paulsen O: Hippocampal gammafrequency oscillations: from interneurones to pyramidal cells, and back. J. Physiol. 2005, 562:55-63.

64. Aivar P, Valero M, Bellistri E, Prida LM de la: Extracellular Calcium Controls the Expression of Two Different Forms of Ripple-Like Hippocampal Oscillations. J. Neurosci. 2014, 34:2989-3004.

65. Cammarota M, Losi G, Chiavegato A, Zonta M, Carmignoto $\mathrm{G}$ : Fast spiking interneuron control of seizure propagation in a cortical slice model of focal epilepsy. J. Physiol. 2013, 591:807-822.

66. Bragin A, Csicsvári J, Penttonen M, Buzsáki G: Epileptic afterdischarge in the hippocampal-entorhinal system: current source density and unit studies. Neuroscience 1997, 76:1187-1203.

67. Bikson M, Hahn PJ, Fox JE, Jefferys JGR: Depolarization block of neurons during maintenance of electrographic seizures. J. Neurophysiol. 2003, 90:2402-2408.

68. During MJ, Spencer DD: Extracellular hippocampal glutamate and spontaneous seizure in the conscious human brain. Lancet 1993, 341:1607-1610.

69. Pan JW, Cavus I, Kim J, Hetherington HP, Spencer DD:

Hippocampal extracellular GABA correlates with metabolism in human epilepsy. Metab. Brain Dis. 2008, 23:457-468.

70. Bragin A, Mody I, Wilson CL, Engel J: Local generation of fast ripples in epileptic brain. J. Neurosci. Off. J. Soc. Neurosci. 2002, 22:2012-2021.

71. Bragin A, Wilson CL, Engel J: Spatial stability over time of brain areas generating fast ripples in the epileptic rat. Epilepsia 2003 , 44:1233-1237.

72. Freund TF, Katona I: Perisomatic inhibition. Neuron 2007, $56: 33-42$.

73. Gulyás AI, Szabó GG, Ulbert I, Holderith N, Monyer H, Erdélyi F, Szabó G, Freund TF, Hájos N: Parvalbumin-containing fast-spiking basket cells generate the field potential oscillations induced by cholinergic receptor activation in the hippocampus. J. Neurosci. Off. J. Soc. Neurosci. 2010, 30:15134-15145.

74. Cohen I, Huberfeld G, Miles R: Emergence of disinhibitioninduced synchrony in the CA3 region of the guinea pig hippocampus in vitro. J. Physiol. 2006, 570:583-594.

75. $\quad$ Cymerblit-Sabba A, Schiller Y: Network dynamics during development of pharmacologically induced epileptic seizures in rats in vivo. J. Neurosci. Off. J. Soc. Neurosci. 2010, 30:1619-1630. 